\title{
Investigating Users' Changing Needs in Relation to Non-designed or Unplanned Public Spaces in Cairo
}

\author{
Joseph M. Namar, Mohamed A. Salheen, Ayat Ismail \\ Ain Shams University, Egypt \\ Joseph.namar@eng.asu.edu.eg | Mohamed_salheen@eng.asu.edu.eg | Ayat.ismail@eng.asu.edu.eg
}

\begin{abstract}
In recent studies, public spaces are defined as living organisms that are subjected to continuous change. These changes affect the different uses of the urban space, its composition and design aspects, in order to cope with the users' changing needs. Rather than that, users intervene in the space formation either formally, by including the community and stakeholders in the design process fully or partially; or informally, by small or big actions done by the space users in order for the space to satisfy their current needs. Several spaces in Cairo are dealt with as leftovers of the buildings design and construction process. These spaces have passed through several changes that affected and was affected by the Cairines (Cairo citizens) and their culture of dealing with public spaces to accommodate their changing needs. The deficiency in public spaces in Cairo urban spaces is reviewed. And the inability of the formal designed/planned spaces to respond to the spaces' users with their changing needs is investigated throughout the research. In order to focus on a public space in Nasr city district in Cairo, sequential mapping to the area over different ages is carried on, examining the changes -formally and informally- in the space to cope with area users. That is accompanied by surveys and questionnaires that aim to determine the needs of the users in the space and whether they are met or not. The questionnaire also aims to measure the level of intervention and satisfaction of the users in this space, to explain how its users intervene in adapting to the existing formal design, and to find out how these interventions shape and affect directly and indirectly the dynamism of the space as a formal planned public space. The paper aims to review and find out theories and practices that provide solutions for dealing with non-designed open spaces development in terms of users changing needs and contributions. The results from the study show some development considerations that need to be respected in Cairo public spaces with more concern for people's usage and interaction with the space.
\end{abstract}

Keywords: changing needs, dynamism of space, Cairo, public spaces, non-designed spaces, leftover spaces, placemaking

To cite this article:

Namar, J. M., Salheen, M. A., Ismail, A. (202I) Investigating Users' Changing Needs in Relation to non-designed or Unplanned Public Spaces in Cairo, The Journal of Public Space, 6(I), 47-66, DOI 10.3289I/jps.v6il.1442

This article has been double blind peer reviewed and accepted for publication in The Journal of Public Space. (c) (1) \$ This work is licensed under a Creative Commons Attribution - Non Commercial 4.0 International License https://creativecommons.org/licenses/by-nc/4.0/ 


\section{Public Realm and Public Spaces}

The term public realm have been approached in many researches by many specialists, academic researchers and experts, who are directly or remotely concerned with the people or the citizens of the city - such as Hannah Arendt (1998) and Jürgen Habermas (1964) in political field, and Michael Brill (1989) and Jan Gehl (1987) in the field of urban design and planning - in order to serve a vital role in the research fields as politics, economics, sociology, planning or landscape and urban design (Goodsell, 2003). For ages authors in many different disciplines have employed the term quite differently such as Jan Gehl in his book "How to Study Public Life" (2013) and Allan Jacobs in his book "Great Streets" (1995) which in some ways may relate to each other to get a better understanding to it. There might be some contrary between how public realm can be identified or distinguished from the social realm and perspective; and how it can be conceived as a physical attribute such as city centre or town plaza from the urban design perspective. That lead experts suggest a more clarified definition to the term "public realm". Researchers tend to examine and study the public realm based on their own specialization and field of study: geographers examine the spatial dimensions of the public realm by exploring the built and virtual environments as places for public life to play out, while political philosophers conceive it more abstractly as the rational space where the state and civil society are enacted, reproduced, and negotiated. Economists deal with the public economic realm as it includes the valuation of public goods and the management of public finances. And last but not least, sociologists address the social public realm as the location of people's everyday interactions and contributions where identities and shared meanings are constructed. Zachary Neal in the Encyclopaedia of Urban Studies (2018) refers to public realm as all aspects of the social world that are not exclusively private (e.g., private property, private life). By which he divided the public realm into multiple overlapping dimensions that have each given rise to distinct theories and modes of investigation, often within the boundaries of specific academic disciplines. Lyn H. Loftland (1998) defined public realms as "not geographically or physically rooted pieces of space. They are social, not physical territories. Whether any actual physical space contains a realm at all and, if it does, whether that realm is private, or parochial, or is public is not the consequence of some immutable culturally or legally given designation. It is, rather, the consequence of the proportions and densities of relationship types present, and these proportions and densities are themselves fluid". In urbanists' point of view, public spaces' definition can be more specific and inclusive. Many have defined public spaces from their point of view as Woolley (2003) tried to simplify the definition in the book Urban Open Spaces, addressing public spaces are arenas for different activities performed by different users in their daily lives. The Charter of Public Spaces provided a more generic but specified definition of public spaces as "Public spaces are all places publicly owned or of public use, accessible and enjoyable by all for free and without a profit motive (Garau at al., 20I3). Public spaces are a key element of individual and social well-being, the places of a community's collective life, expressions of the diversity of their common, natural and cultural richness and a foundation of their identity. The community recognizes itself in its public places and pursues the improvement of their spatial quality.

Recently, urbanists and socialists started to agree on dealing with public spaces in both perspectives combined together. Allowing better improvements and focusing on the community itself and their interaction with the physical spaces. They emphasis the 
direct relation between cities improving their public spaces and the enhancement of community cohesion, quality of life and citizens civic identities (Garau, 20I6).

But the question emerged is whether public spaces now are good enough for the public in their daily uses or not, and how can the space and the community affect and be affected by each other. In a recent study for Project for Public Spaces (20I5) produced a diagram (Figure I) that shows the economic, social and environmental values of public spaces in recent times.

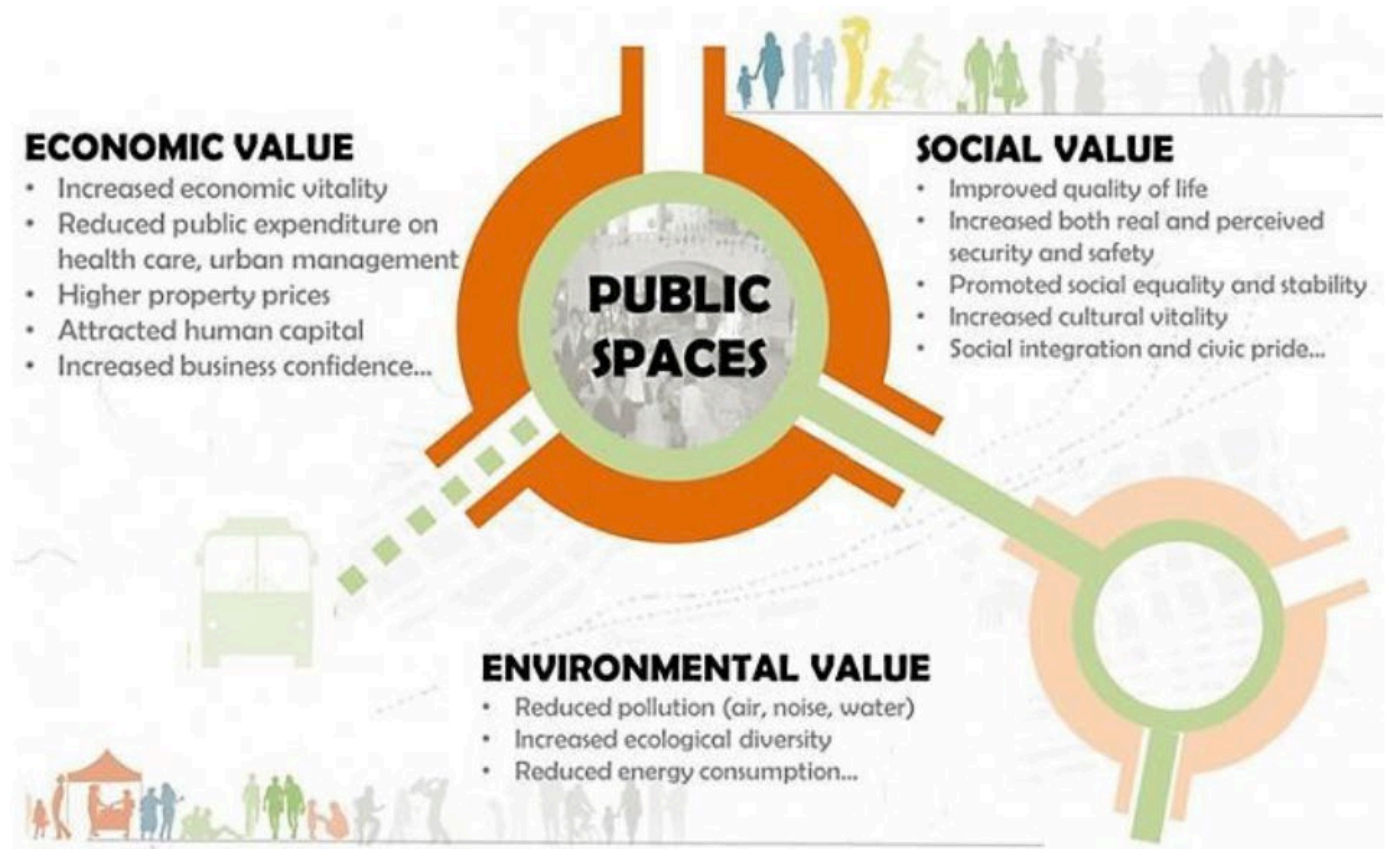

Figure I. Economic, social and environmental values of public spaces. Source: Project for Public Spaces.

\section{I.I Non-Designed and Leftover Spaces}

Dealing with open spaces, it can be noticed that there are some spaces that end up abandoned or empty of design elements that can't fulfil the definition of public spaces. Leftover spaces can be found in different forms and as a result of different actions. For example, non-designed and leftover spaces can occur to exist next to a designed and planned development, underneath bridges, along high-ways or as backyards or vacant areas in a building complex. (Qamaruz-Zaman, et al., 20I2)

Non-designed and leftover spaces have been defined in several terminologies as "spaces of uncertainty" (Cupers \& Cupres, 2018) "urban voids that are considered unutilized, unnoticed or meaningless by a large segment of community" (Akkerman \& Cornfeld, 2009/20 I0) or "no man's land" (Groth \& Corjin, 2005). This kind of spaces are mainly characterized by the lack of officially assigned or designed uses, abandoned, not developed and they act as the backside of the primary designed and planned uses of the public space. This kind of spaces can be considered either as negative misused spaces or potential public spaces for future interventions. 


\section{Public Spaces Change}

Over time public spaces have been in continuous changes coping with political, economic and social factors. Those factors might affect directly and indirectly how and why public spaces are designed. Several approaches were used on spaces to be dealt with, that can be classified as shown in Figure 2 into three main approaches as follow (Woolley, 2003):

- Traditional approach.

- Modernism approach.

- Post modernism approach.

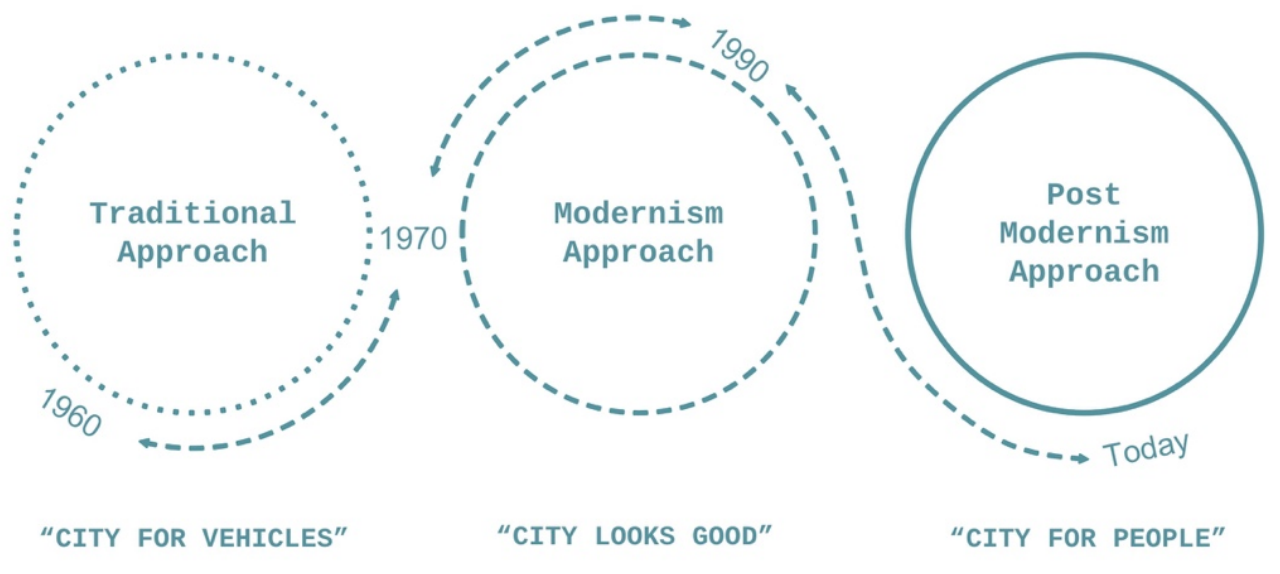

Figure 2. Development approaches periods. Source: authors.

The traditional approach which emerged in the period from 1960s to 1970s was a response to the evolutionary demands of the society back then. It acted as a movement of renewal to public spaces which have been affected and ruined as result of wars (van der Werf, 2016). Trying to deal with emerging challenges as low urban quality, poor life conditions and the focus on developing the city and public spaces to fit with the vehicular uses only (city for vehicles) (Gehl, 2003). In her book The Book and Life of Great American Cities, Jacobs commented on how cities should consider pedestrians as well as vehicles. She claimed that "Cities have the capability of providing something for everybody, only because, and only when, they are created by everybody." (Jacobs, 196I). This kind of development resulted in a polluted environment with low quality public spaces that barely meet the needs of the pedestrian use. Followed by that, appeared the modernists approach as discussed by Loukaitou-Sideris which took place during the period from 1970s to 1990s (Loukaitou-Sideris, 2006). Treating the public spaces, the modernism approach was concerned more with the aesthetic side of the space as Gehl argues that the involvement of architecture has contributed in the improvement of public spaces aesthetically to be more pleasing to public use yet can provide a wholistic solution to all the issues plaguing open spaces (Gehl, 1987). Flowingly the post modernism era emerged which continues to our recent times nowadays but have evolved throughout time. Post modernists started focusing on issues of "life in the city and the interplay between urban life and public space" (Gehl, 20I0). In the last decade the focus of public open spaces has changed to highlight the importance 
of urban liveability and the important role of the public open space environmentally, socially and economically to embrace space sustainability and sustainable public spaces.

\section{I Development evolution}

Dealing with public spaces have been developing over time. Getting affected by political directions, economic factors or social changes throughout history. According to Place Making approach on their release, as in

Figure 3 the relation between the way of dealing with public spaces and how it affects the community (Projects for Public Spaces, 2007).

I. The project-driven approach is a type of top-down process that is led mainly by the government or the authority, it results in a space that follows a general protocol or system with no respect or fulfilment of the public local needs (Southworth 1989).

2. The discipline-led approach is the type which depends on a specific single vision in the design, for example urban designers or other professionals. Spaces started to look more attractive aesthetically but haven't succeeded to be a good attractive space for public users (Barnett 1974).

3. The place-sensitive approach is the type of spaces which depends on space designers to gather community input and needs in a public space in order to develop it. Yet it is still led by architects and urban designers (Linovski and Loukaitou 20I2).

4. The place-led approach relies in its basis on not just the input of community needs before the design process, but also their involvement and engagement in the design process and output of the public shared space. This approach helps improving a space that can cope with the changing needs of the public using their own space (Projects for Public Spaces, 1978).

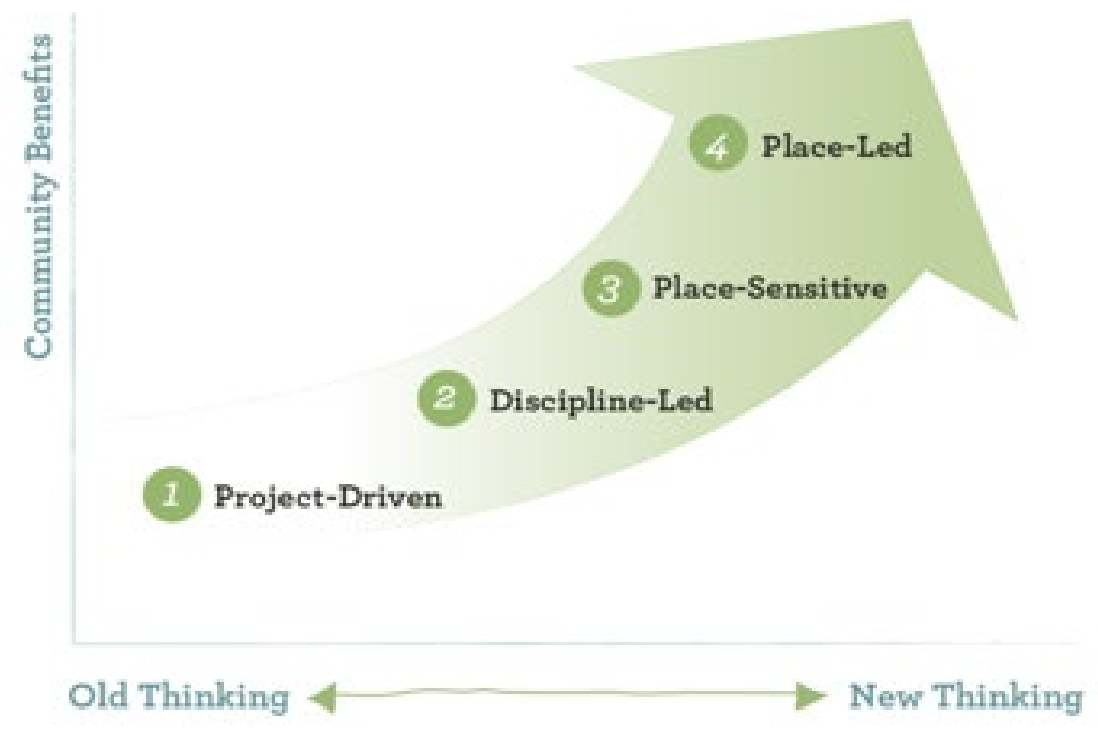

Figure 3. Evolution development over time. Source: Project for Public Spaces. 


\section{Research Problem}

It has been noticed in many places around the world how a good public space can attract the city residence for social interaction, physical activities and ecological benefits. But what about our local public spaces in Egypt or in the city of Cairo specifically as the heart and capital of Egypt, when we look at our public spaces are we able to define these spaces or get the functions of these spaces? are the users benefiting the social, physical and economical aspects of the spaces? If we compared the local public spaces to the well-known successful public spaces, we will find a gap between what the public spaces should act like and what they are actually like and this affects the residence quality of life and their sense of well-being (Singerman, Amar, 2009). Concerning public spaces in Cairo urban fabric can be noticed that they exist physically. Cairo public spaces might be left during the design phase as open spaces between the urban fabric, but do they achieve the purpose of their design, do they interfere in people's lives positively and allow them to have the quality of life that Cairo residence deserve. The research will be studying the deficiency in public spaces in Cairo urban fabric and the inability of the formal designed/ planned spaces to respond to the space users changing needs. Throwing focus on how the users dealt with this deficiency over time and their interventions in non-designed and leftover spaces in Cairo in order to cope with the problems facing them in a public space.

\section{Case Study: The international Garden Area in Nasr-City}

Nasr city, one of the main districts in eastern Cairo that was excited based on Egyptian president Gamal Abd El-Nasser's decision of building a new district in the desert part of Cairo back in 1959 (Abouelmagd, 20I I). The master plan and urban design of the district designed by Dr. Sayed Koreim is based on a grid pattern that divides Nasr city into neighbourhoods. These neighbourhoods are designed adjacent to each other with central nuclei containing the activities and services of each zone with a bigger servicing and entertainment centre for each group of neighbourhoods (Reconstruction, 2019).

The urban morphology of Nasr city has gone through several changes and transformations, which can be viewed when the actual urban state is compared to the proposed and first executed state (Selim, 2016). The paper focus on one of the urban areas in Nasr city district which is considered one of the biggest breather spaces in the whole urban area of the district, as it is considered the biggest garden and green area in this morphology, the international garden. The paper will focus on the strip of buildings and spaces overlooking the northern side of the international garden. Which contains some retail shops, cafes and restaurants with an outdoor public space used by several types of users such as area residence, youth and families seeking some entertainment or passers-by.

\section{I Methodology}

In order to understand the deficiencies a space can go through, and to study the interventions and the changes that users add to the place to cope with their changing needs the case is mapped showing two main phases, the initial state that was dealt with as a leftover of the project design and the current situation of the urban formation of the space in order to observe the changes the space has gone through. To be able to understand and assess these changes and their effects, field observations are carried on 
in different timings of the day and night to monitor the type of activities and the way of usage of the users to the space changes; in addition, online and field questionnaire was distributed on the space users aiming to understand and measure their satisfaction of the current situation of the space and the changes by questioning if the space meet their needs.

The mapping of the site depending on showcasing the pre-design and initial construction of the space in comparison to the current physical situation focusing on the main areas that have fallen under changes by the users that affected the hardscape, softscape and light furniture of the spaces. While the questionnaire was constructed to measure the users' needs and if the space meets these needs or not based on the common main needs that should be provided in a space based on literature. The questionnaire is then accompanied by an overlay of the spatial observation of the users' allocations in the space and its relation to the physical attributes and the activities taking places in the space.

\subsection{Space Changes}

By viewing the initial design of the space as shown in Figure 4, it can be observed that the area wasn't designed putting in consideration the users' needs in the landscape of the space as it was plain and treated as a leftover space of the built-up area of the residential buildings.

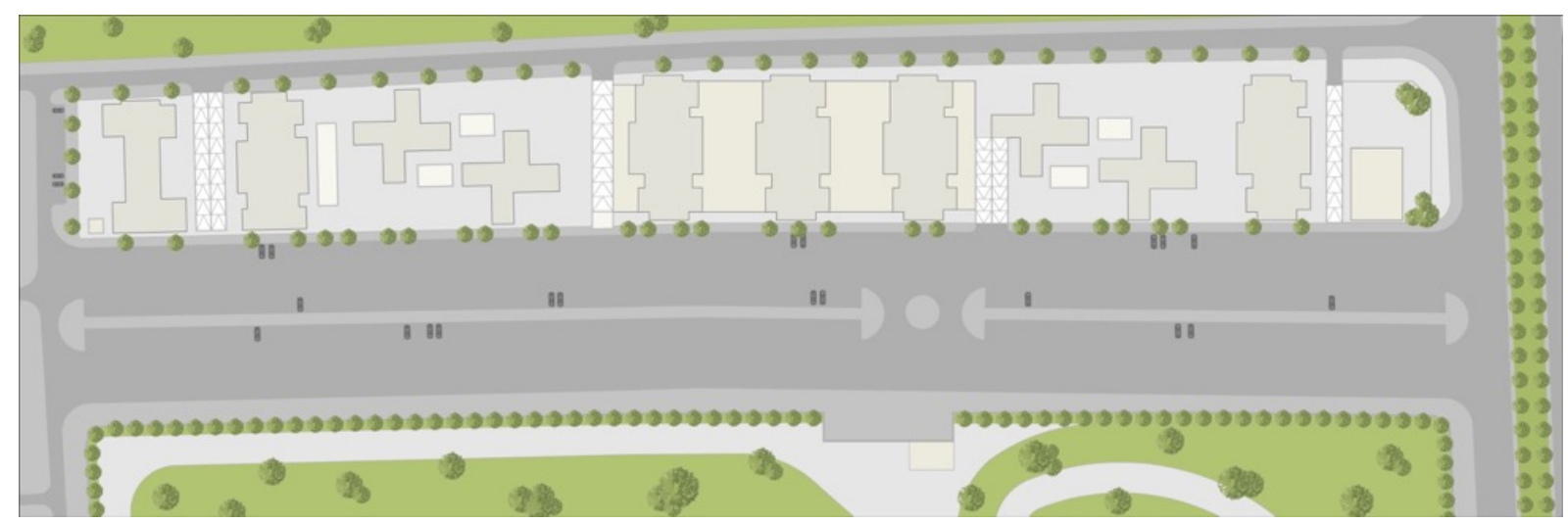

Figure 4 - The initial map of the public space in front of the International garden of Nasr city. Source: Authors

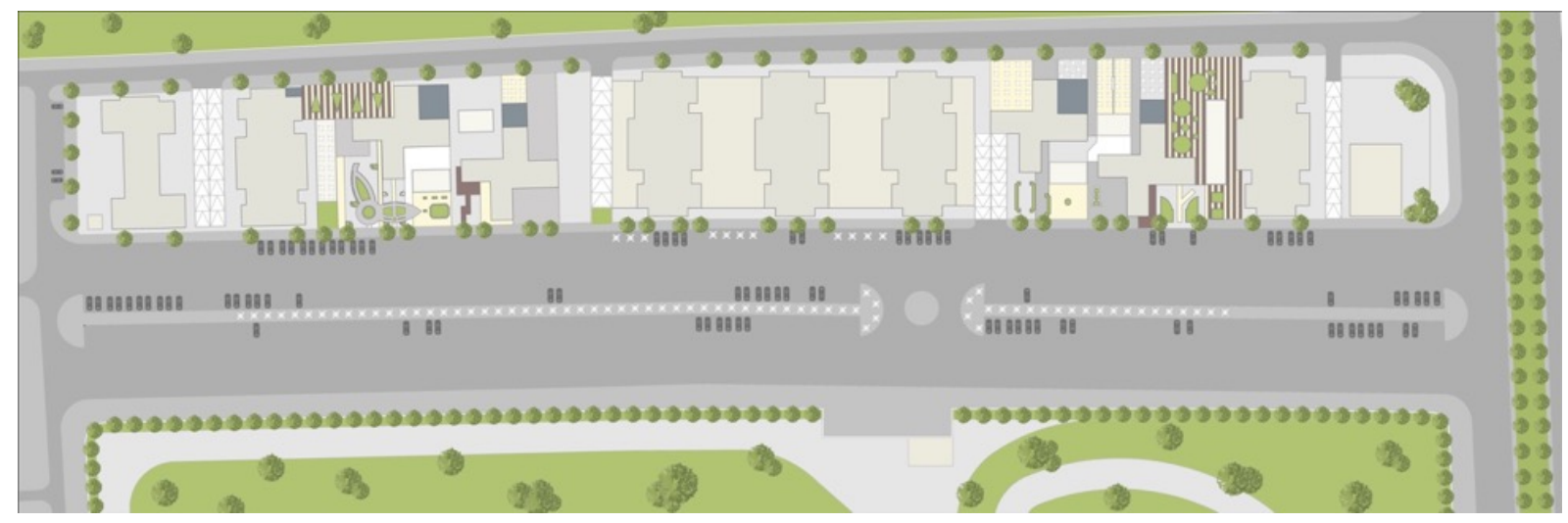

Figure 5. The current map of the existing situation - 2019. Source: Authors. 
Throughout time users have made some interventions in the landscape and buildings in order to accommodate their changing needs that haven't been fulfilled in the initial design. When leaving a space non-designed and not fulfilling its purpose as a public space, users of the area don't have the power or resources to develop the space in order to meet their own needs. Therefore, shop owners (in this case) whom have the power and motivation to make change end up taking the action of intervention to be a win-win situation to both space users and the shop owners themselves to build up their business.

Figure 5 maps the general interventions in the space which are in different typologies and can be for different purposes that serves several types of the space users.

\subsection{Interventions Typologies}

On decades time scale for the area, it can be noticed that many interventions took place by the users of the space, mostly are for commercial purposes or to serve and attract the target users of the space. These interventions can be classified into three main typologies shown in Figure 6 that are viewed in the space which are:

I. Encroachment.

2. Place appropriation.

3. Movable modifications.

\section{Encroachment}

These are empty spaces in the initial designs at which cafes and restaurants owners decided to add enclosed light structure to increase their area and territory in order to attract and accommodate more clients to their existing area which can be seen in the existing map in the dark blue coloured zones. The encroachments of the restaurants and shops can be sometimes legal or illegal.

\section{Place appropriation}

These used to be areas between buildings which weren't used well or even used at all as they didn't have main landscape elements as seating areas, shaded areas or even green areas. The residents and shop owners hired consultants to construct these areas in order to accommodate the users' needs and attract more people to the whole area. Those zones are shown in the existing map and can be recognized as four main zones. Two of them are in the frontal area of the buildings serving more commercial purposes while two other zones in the back area of the buildings serving the buildings residents and users more.

\section{Movable modifications}

These are just street furniture as seating, tables and umbrellas that are added and removed daily by the cafes and restaurants to accommodate more users in the peak hours of the area getting benefit from mostly all the pedestrian areas of the space and on top of the underground parking ventilation areas. Leading sometimes to crowding and blocking the accessibility in some areas in the space and can be shown and noticed in the existing maps compared to the old situation. 


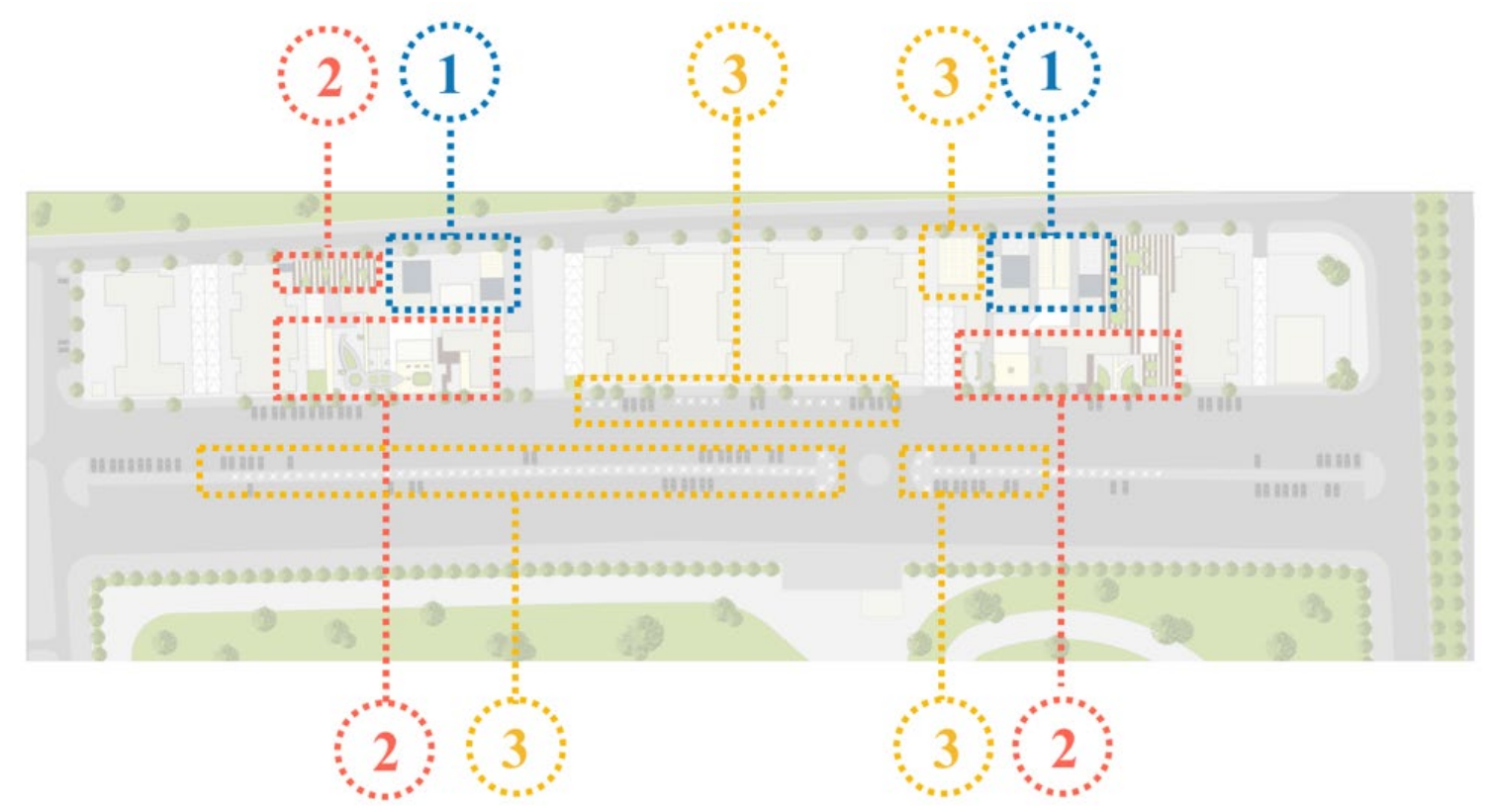

Figure 6. Intervention typologies. Source: Authors.

\subsection{Users Needs in Public Spaces}

"Why do people go to public spaces?", a question that pops up when studying the social community and their relation to urban forms. Many of the reasons of people spending time in public spaces is their need as human beings to interact and escape city crowd and noise somewhere (Milgram, 1970). That's why this leads them to find spaces where they can practice whichever activities that help meet their needs.

That leads us to find out what kind of needs that users seek in spaces in order to attract them and fulfil their urge to spend time in public spaces. According to the book "Needs in Public Spaces" (Carr, et al., 1992) it is summed up that there are five main reasons that account for people needs in a public space which are comfort, relaxation, passive engagement, active engagement and discovery. In order to avoid misuse or quitting of people to spaces it is so important to understand their needs and how can they be met. "Projects for public spaces" in their issue "Placemaking" (Projects for Public Spaces, 2007) researchers tried to provide a new modern module for understanding people needs in public spaces by summing users' needs into four main key attributes that should be achieved in order to satisfy the public realm which are:

I. Access and linkage: spaces are accessible and well connected to other important places in the area.

2. Comfort and image: spaces are comfortable, safe and project a good image.

3. Uses and activities: spaces attract people to participate in activities in the spaces.

4. Sociability: spaces are social environments in which people want to meet up again and again.

These four attributes were interpreted and expressed in a form of question that can measure the level of achievement of each of them in a space in order to measure the people's satisfaction of the selected space after the changes and interventions it has gone and is going through. 


\subsection{Focus Area}

This paper is focused on a specific space in the whole area that shows one of the biggest changes over time. The selected space shows several types of interventions in one space that can be significantly noticed by just observing the space as it is seen in the site pictures in Figure 7.
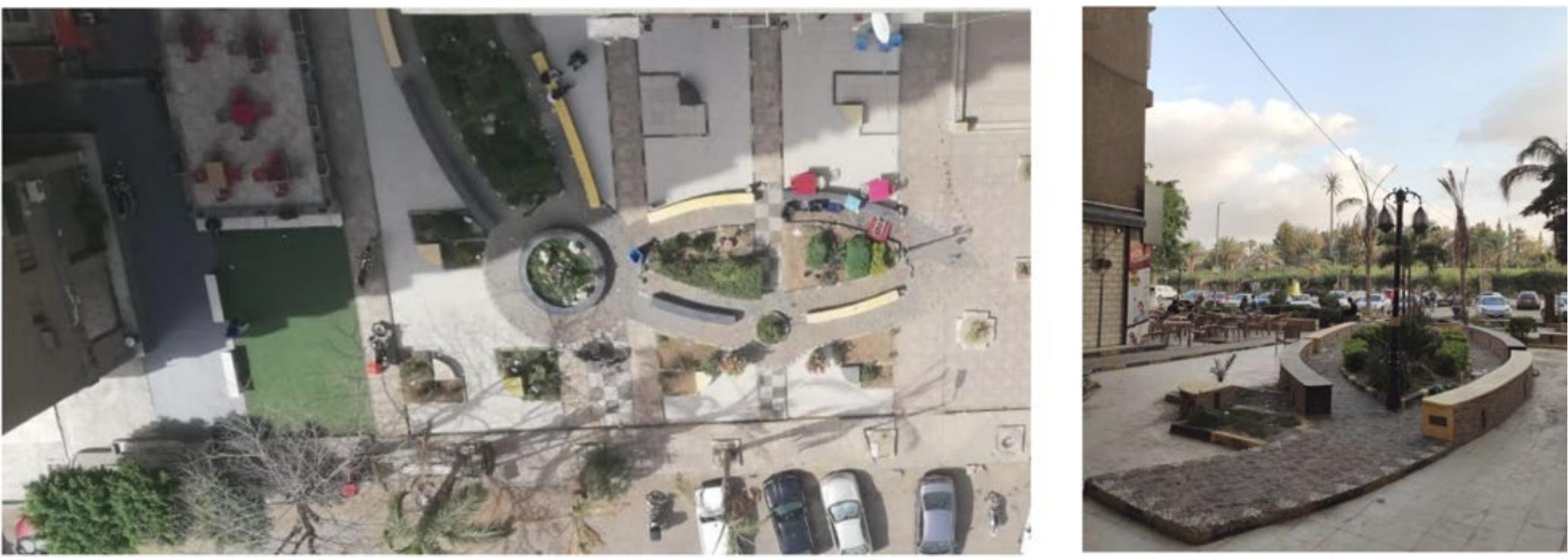

Figure 7. Site pictures showing the current landscape design of the focus area. Source: Authors.
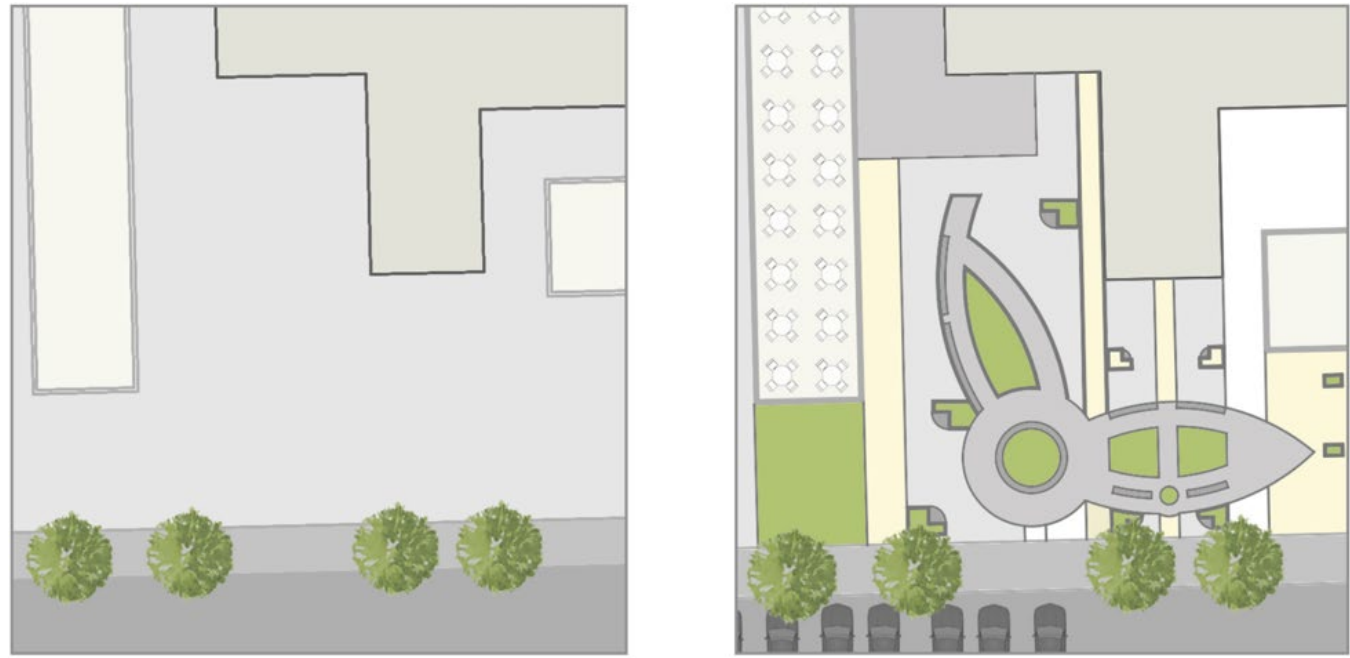

Figure 8. The before and after mapping of the focus area. Source: Authors.

The following Figure 8 shows the mapping of the area at its first stages and the result of the changes applied on the landscape design. These changes happen to be resulted by shop owners of this area who collaborated and hired a landscape company to redesign this area based on their needs of an active attracting public space that contains a proper seating area, green areas with some plantation and a different tiling than the 
surroundings in order to attract more customers to their provided products. Other area on the space is the ventilation area of the underground parking on which restaurants used its super platform as a levelling that accommodate light street furniture of tables and chairs and providing stairs to make it accessible to the space users.

\subsection{Spatial Analysis}

The new current formation of the space is designed to provide a better use from the shop owners and space users perspective to cope with their changing needs. In order to understand the space well a street section is drawn in Figure 9 to allocate the kind of activities and interventions in the space and how do the people deal with them.

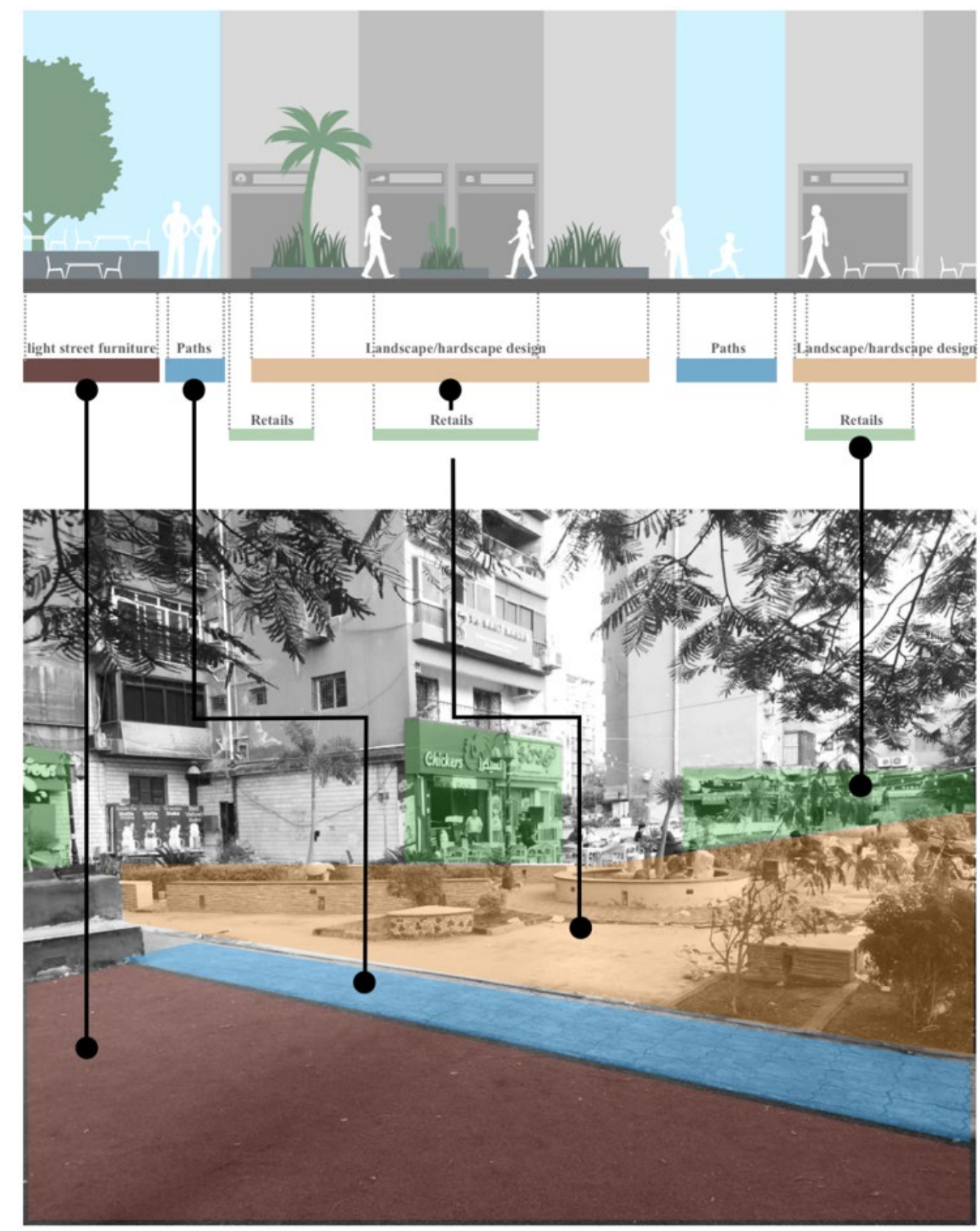

Figure 9- Visual and functional analysis of the focus area. Source: Authors. 
The red section is the area on which light street furniture as seating, tables and umbrellas are spread before the beginning of the arrival of cafes customers at day time and collected every night after the day is over, the light blue sectors represent the pedestrian paths that are considered in the design to provide accessibility to the shops and the back area of the buildings, the orange sectors represents the hardscape area designed to accommodate fixed seating areas, green areas with plantations and different tiling in order to specialize this zone for the users, While the green sectors identify the existing main activity in the space which is the food and beverage services provided by the shops highlighted in the section.

To get more understanding of the space field observations of the users type as for gender, age and number and their allocation in the space. The field observations are used to get insights of how the users deal with the space than getting frequencies of the space usage. The focus area was visited on several days over the day and night to get more comprehensive understanding of the kind of activities that takes place in the area and what attracts more people to the area. Several maps of users of different days took place. The observation of the field was done on specific timings of the day with a margin of 3 hours between each map in order to get better image of how the users deal with the place, what attracts them and in what times are some areas of the space crowded or not.

A random day of the week is picked and mapped for the periods 1:00-1:30 PM, 4:004:30 PM, 7:00-7:30 PM and 10:00-10:30 PM focusing on the numbers and locations of male and female users of the space with only spotting the users standing or sitting in the space, excluding the passers-by in the area. Then an overlaying of the 4 maps is done and shown in Figure 10 showing the most attracting spots for the males as the blue spots and the females as the red ones.

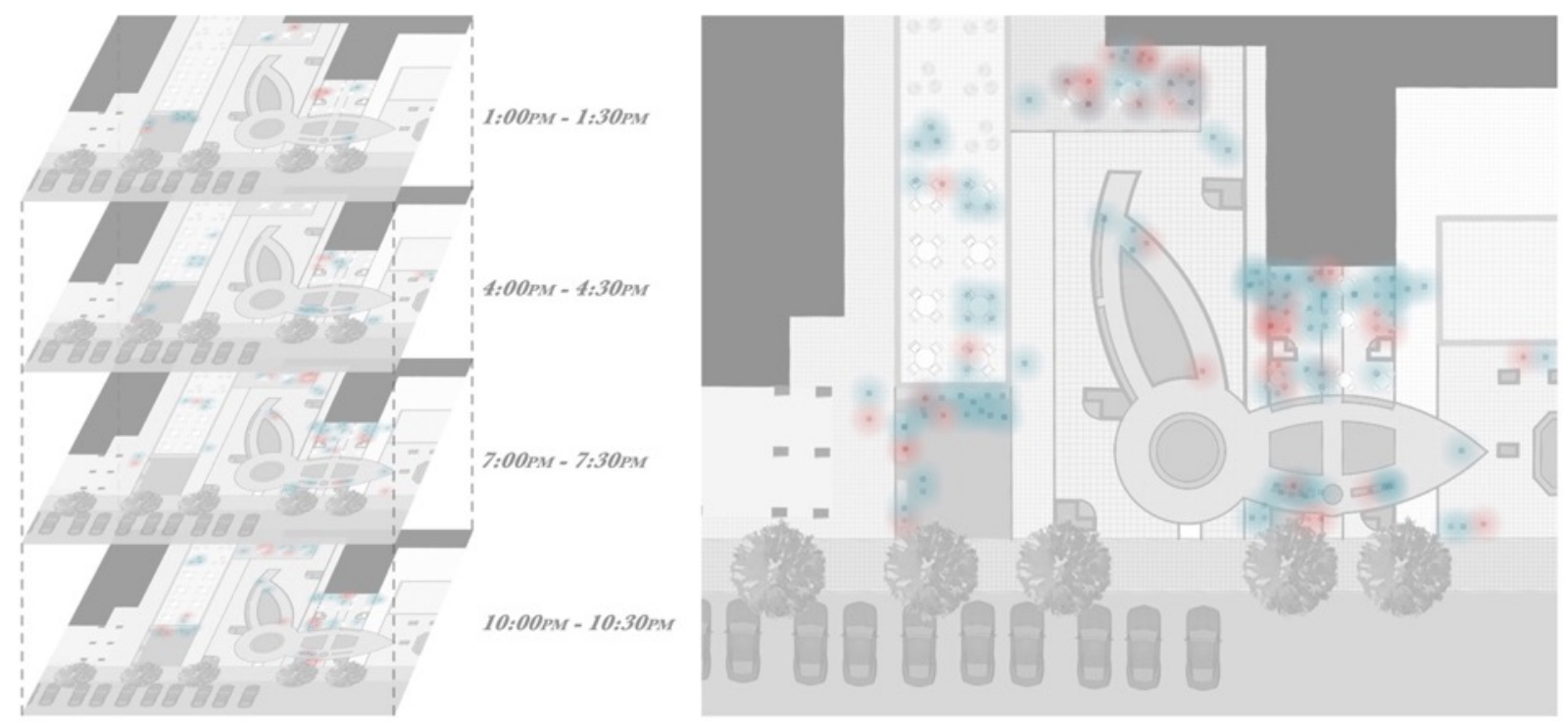

Figure 10. A map showing the overlay of users' locations along the whole day. Source: Authors 


\subsection{Findings}

In this section the research findings are divided into two sections. The first section focuses on the observations noticed, analysed and categorized in order to have better understanding of how users deal with the space to deal with its problems and deficiencies in order to meet their needs. The second part is based on the results of the questionnaire measuring the current users' feedback and comments on what the space have achieved ad what my still be missing from the current situation.

\section{I Intervention Purposes}

Based on the previous analysis provided in the previous section that is structured on observing and mapping of the space with its modification compared to its original nondesigned form, it is concluded that there are different types of motivation leading the interventions applied upon the space by the users for different purposes which can be summed up into three main purposes which are; functional purpose, aesthetic purpose and territorial purpose.

\section{I.I Functional purpose}

One of the main and straight forward interventions done by the users as a direct response to their need to an accessible place is translated into direct pedestrian paths that connect the users from the main pedestrian sidewalks to the buildings' entrances or by the shop owners to the areas around the shops and restaurants which is represented in Figure II. Intervention purposes in the focus area. Source: Authors.as the blue coloured directional areas. Some of the paths were existing already in the initial state but due to the lack of maintenance and the deterioration of the paving materials, the new interventions applied new defined paths with different paving materials to ensure on the main functional paths in the space leading from one point to another.

\section{I.2 Aesthetic purpose}

The aesthetic purpose is a kind of motivation that exists and generate due to the need for users to have a good-looking attractive place that can provide a good image for the space. It was applied in the space by providing natural plantation that improve the whole landscape design of the space and enrich the hardscape and softscape design which represented in Figure II as the orange zone. Also, the design in this space is based on a geometric shaped design that can be viewed either by the human scale users on the ground level or by the approach of the terraces overlooking the space which makes it significantly different and unique than the whole surroundings.

\section{I.3 Territorial purpose}

Several activities and interventions in spaces can be considered done for territorial purposes as these actions are directly and indirectly a way for the users to spread their territory and sense of controlling of the space which is represented in Figure $\mathrm{II}$ as the light red colour and also the orange zone can fall under the umbrella of territorial motivation. In this space this kind of action is noticed in the case when restaurants and cafes overlooking the space try to expand their territory by adding small fences, using temporary furniture like light chairs or bean bags, or land covers or tiles in order to be able accommodate more customers with the intention of increasing their revenue. 


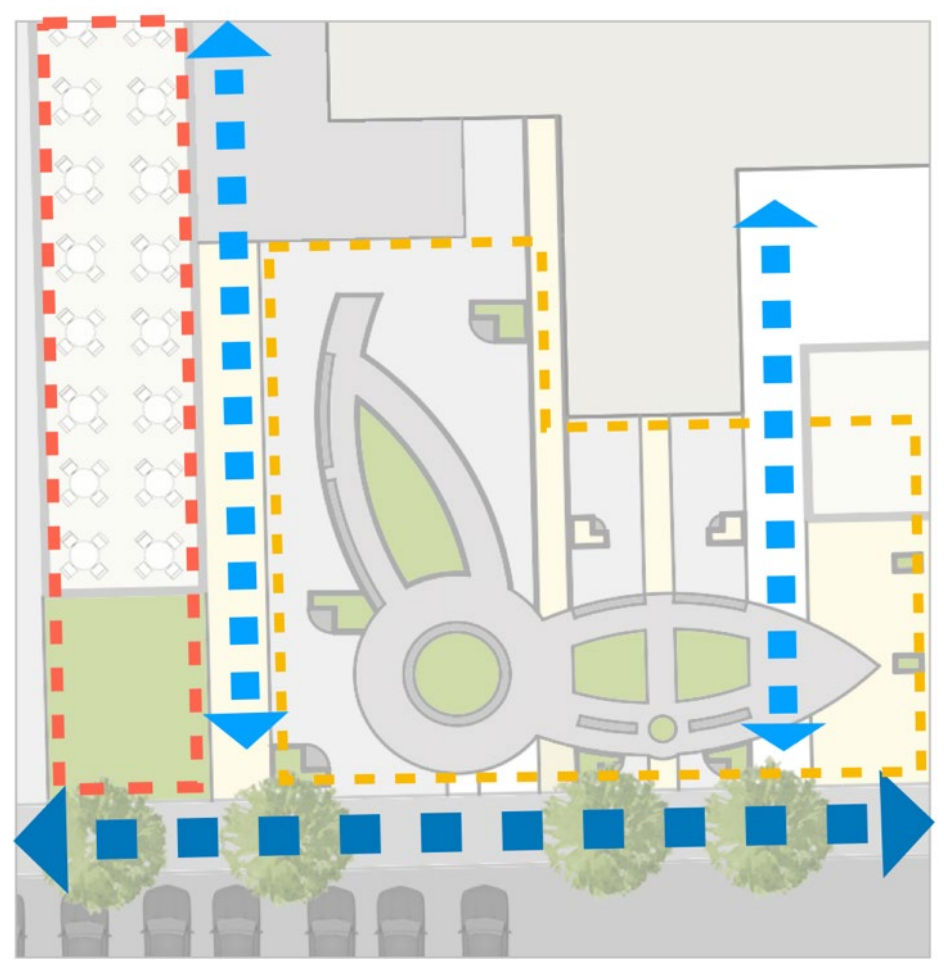

Figure II. Intervention purposes in the focus area. Source: Authors.

\subsection{Questionnaire Results}

This part of the research aimed to understand how the changes in the physical attributes affects the users and their perception and way of dealing with the focused areas in the space. The questionnaire was distributed in a physical and online form to the space users and residence with a total of 52 responds that are divided into $56 \%$ of male users and $44 \%$ of females. The respondents age range in category from 19 to 45 years old however most of the respondents are between $3 \mathrm{I}$ and 45 years old. In order to have more understanding of the type of users in the space the users were asked about the kind of activities they visit the space for which turned out to be that $63 \%$ visit the space for food and beverage activities as restaurant, cafes and fast food shops while $23 \%$ are into walking and jogging through the space, $10 \%$ seeks relaxation in the space while the rest visit for other activities, which explains that people mainly are attracted to the space for the purpose of eating and drinking in an open space.

\subsection{Analysing the Needs of The Community}

The second sector of the questionnaire tried to measure how much does the space meet their needs based on the four main key attributes of placemaking offered by PPS.

The following

Table I shows the type of attribute to test and how it was translated into a question that reflects how much this attribute is achieved in the space to accommodate the needs of the users in the current setting of the landscape.

The last sector of the questionnaire targeted understanding the awareness of the users with the changes happened in the space and how they feel towards these changes. 
Table I. Questionnaire questions and results reflecting placemaking attributes

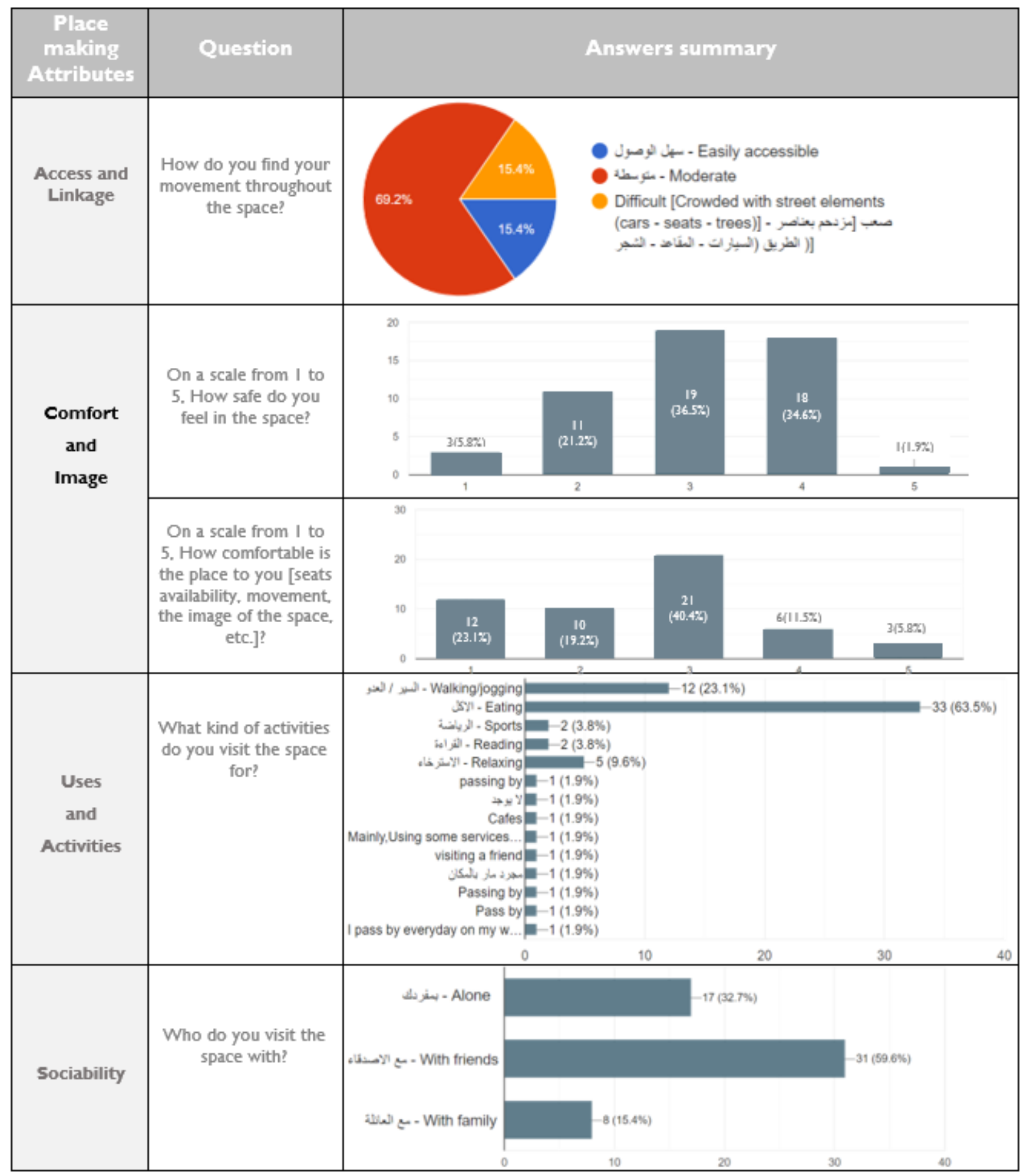


The results showed that $63 \%$ of the people who have noticed the changes in the space think that these changes helped to improve the space. Last but not least, an open question was provided for the users in order to express from their perspective what can be done in the space in order to increase their satisfaction of the space environment; most of the comments requested a better and cleaner seating areas, more lighting spots at night as some areas might seem unsafe by night, more shaded areas by the day either by plantation of shading devices, and children friendly areas within the space. One of the comments that was added by the area residents was "Having my apartment in this street my whole life made me realize that being a little more vibrant and crowded is much better from safety point of view than when it was just an empty space. Lack of proper seating and relaxing areas is one problem. The main activity of the entire street is food, there isn't really much else to do. And this space is mostly used starting evening, and night-time, there is nothing much to do in the morning, there isn't even any place which serves breakfast, they're all mostly closed in the morning so the space is kind of wasted a little without suitable shades and seats for morning time."

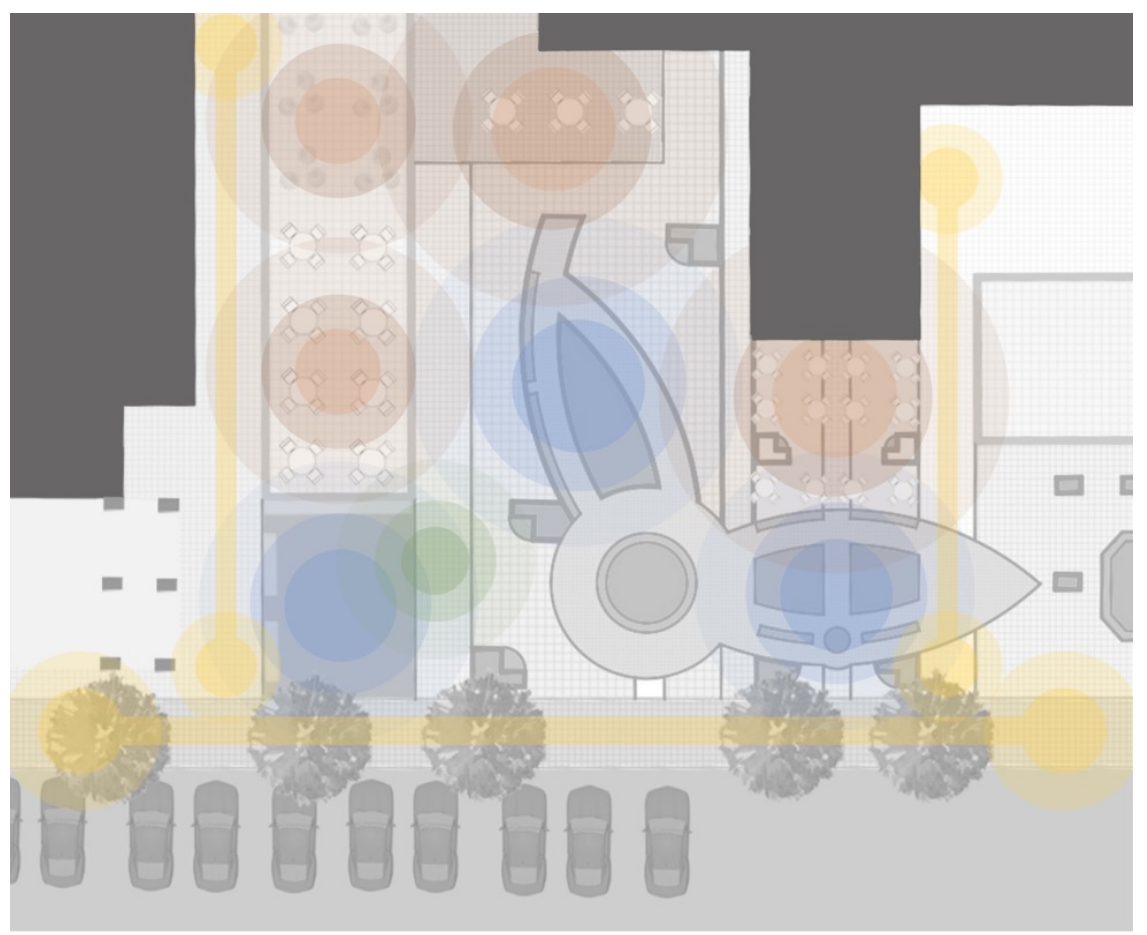

Figure 12. Activities map of the focus area. Source: Authors.

\subsection{Activities mapping}

Following the users' concentration spots and the questionnaire results, a relation between them is established to show what kind of activities take place most in the focus area and their connection and effect on the users' movement and assembly in the space Figure 12 shows the main activities in the area and their circle of effect on attracting the users, where the yellow lines show the paths that carry the most flow of moving along and through the space, the orange zones are the ones where users use for food and 
eating activity, the light blue zones are the areas where users use for relaxation and socializing because of the seating within the landscape and between the greenery and the trees, while the green zone represents the area where couriers of the surrounding restaurants rest and park their motorcycles so it is mainly a waiting area for them. The unmarked zones are the most vacant areas that are mostly abandoned by people in the area.

It can be noticed that the space was influenced directly and indirectly by the changes, turning from a vacant space to a public space that can accommodate users' needs and activities. The people are benefitting from the activities offered by the place with the landscape facilities that helps providing their needs of comfort, safety and entertainment in the space.

\section{Discussion}

In order for the paper to understand the deficiency in the selected space and how did the users tried to cope and overcome the lack of main needs in the space, physical and motivational analysis are conducted. The observed interventions are either for functional, aesthetic or territorial purposes have impacted how the users feel and what they perceive in the space which is devised and explained in the questionnaire results and the spatial analysis. Which shows that there is a direct relation between the types of interventions mentioned in the space and the users' satisfaction of their current and changing needs. It can be deducted that the more the space was developed and considered the needs in the space such as providing functional direct paths, proper seating areas and more attractive landscape design; the more users feel easy to move through the space, spend more time in the space and feel safer as the existence of people attracts more people to public spaces. The space has gone through changes that turned the leftover open space of the initial design of the area into a public space that is resembled in seating areas and small gardens publicly accessible to the neighbourhood users of all kinds, genders and ages. Despite these changes the space has gone through it still doesn't meet all the users' needs in a space and the users still feel that the space can offer more to increase the quality and the state of the place as a vital public space.

\section{Conclusion and Considerations}

The paper has shown that there have been some changes in the landscape design of the selected space. These changes were carried on by some of the community (shop owners and neighbourhood residents) using and benefiting from the space in order to meet some demands and increase their personal benefits in the space. Which in a direct and indirect way affected all the users of the space either socially, economically or physically, and attracted more people to the space that resulted in contributing to the general satisfaction of the users.

Community involvement in the design process is one of the most common approaches used nowadays in public spaces design as the spaces are designed by and for the people. The research shows that the people's needs are dynamic and are always subjected to change that's why the design process should be a continuous process that involves people feedback and sometimes the construction phase as well. Placemaking is considered one of the most adapted place-led approaches that put the people first in 
the design, construction and management process of a space. In the chosen case study, the space was dealt with as a leftover that was not considered in the design phase of the area, but that was a good opportunity for the users in the area to have a role in the design of the space as a reaction to their changing demands and needs along the time. The paper used the four main principals of placemaking to study the space and measure the effect of the users' interventions in the space resulting from their needs. The results still show some deficiencies in the space that needs to be considered within the area yet, it shows a story of success even slightly to cope with the users demands for a proper public space from their own viewpoint.

The study throw attention on the importance of putting people first when it comes to public spaces design as people are the main users and their existence and functionality is what makes a public space liveable and acting as a place. As a conclusion from the paper to be considered in future applications in Cairo public spaces it is crucial give attention to the non-designed and leftover spaces that can be spotted a lot in the city and to notice the dynamic change of users' needs and not only focus on the designers' perspectives but also the users' perception of a space and their aims and right for the space to act as their live breather in the dense, crowded and polluted urban environment they deal with in Cairo. Which would result in creating public spaces that are capable of achieving their main purpose of improving the Cairines quality of life through their daily experiences in open spaces.

\section{References}

Abouelmagd, D. (20II) Public Housing and Public Housing Policies in Greater Cairo, European Network for Housing Research (ENHR) Mixite an urban housing question, Toulouse 5-8 July. Retrieved from https://www.enhr.net/documents/2011\%20France/WS09/Paper\%20ABOUELMAGD\%20Doaa-\%20WS09.pdf

Akkerman, A. and Cornfeld, A.F. (2009) "Greening as an urban design metaphor: Looking for the city's soul in leftover spaces," Structurist, (49), pp. 30-35.

Arendt, H. (1998) The Human Condition. 2nd ed. Chicago: The University of Chicago Press.

Barnett, J. (1974) Urban design as public policy: Practical methods for improving cities. New York: Architectural Record Books.

Brill, M. (1989) "Transformation, Nostalgia, and Illusion in Public Life and Public Place". In: Altman I., Zube E.H. (eds) Public Places and Spaces. Human Behavior and Environment (Advances in Theory and Research), vol 10. Springer, Boston, MA. PP 7-29.

Carr, S., Francis, M., Rivlin, L. G., \& Stone, A. M. (1992) Public Space. Cambridge: Cambridge University Press.

Cupers, M. and Cupres, K. (2018) Spaces of Uncertainty. Ist ed. Berlin: Birkhäuser.

Earl, E. (2009) Encyclopedia of Urban Studies. California: SAGE publication.

Garau, P. (2016) Global Public Space Toolkit. Public Space in the Global Agenda for Sustainable Urban Development. Nairobi: UN-HABITAT.

Garau, P., Lancerin, L. and Sepe, M. (2013) The Charter of Public Space, Biennale Spazio Pubblico \& UN-HABITAT [online] https://inu.it/wpcontent/uploads/Inglese_CHARTER OF PUBLIC SPACE.pdf

Gehl, J. ( 1987) Life Between Buildings. New York: Van Nostrand Reinhold. 
Joseph M. Namar, Mohamed A. Salheen, Ayat Ismail

Gehl, J. and Gemzøe, L. (2003) New City Spaces. Copenhagen: The Danish Architectural Press.

Gehl, J. (2010) Cities for People. Washington DC: Island Press.

Gehl, J. and Svarre, B. (2013) How to Study Public Life. Washington DC: Island Press.

Goodsell, C. T. (2003) "The Concept of Public Spaces And Its Democratic Manifestations," The American Review of Public Administration, 33(4), pp. 36I-383.

Groth, J. and Corjin, E. (2005) "Reclaiming Urbanity: Indeterminate Spaces, Informal Actors and Urban Agenda Setting," Urban Studies, 42(3), pp. 503-526.

Habermas, J. (1964) "The Public Sphere: An Encyclopedia Article," New German Critique, 3, pp. 49-55.

Jacobs, A. B. (1995) Great Streets. Cambridge: MIT Press.

Jacobs, J., (196I) The Death and Life of Great American Cities. Random House.

Linovski, O. and Loukaitou, A. (2012) "Evolution of Urban Design Plans in the United States and Canada: What Do the Plans Tell Us about Urban Design Practice?" Journal of Planning Education and Research, pp. 66-82.

Loukaitou-Sideris, A. (2006) "Is it Safe to Walk? Neighborhood Safety and Security Considerations and Their Effects on Walking," Journal of Planning Literature, 20(3), pp. 219232.

Milgram, S. (1970) "The Experience of Living in Cities: Adaptations to urban overload creates characteristic qualities of the city life that can be measured", Science, I67(3924), p. I46 I1468.

Nasr City Company for Housing and Reconstruction (2019) Madinet Nasr for Housing and Development. Available at: https://mnhd.com/about-us/ (Accessed: August 5, 2019). 
Investigating Users' Changing Needs

Projects for Public Spaces (1978) Exxon Minipark: A Re-design and Management Proposal. New York: P.P.S.

Projects for Public Spaces (2007) What is Placemaking? Available at: https://www.pps.org/article/what-is-placemaking (Accessed: January 5, 2019).

Qamaruz-Zaman, N., Samadi, Z. and Farhanah, N. (20I2) "Opportunity in Leftover Spaces: Activities under the flyovers of Kuala Lumpur," Procedia - Social and Behavioral Sciences, (68), Pp. $45 I-463$.

Selim, G. (2016) "Between Order and Modernity: Resurgence Planning in Revolutionary Egypt," Journal of Urban History, 42(I), pp. I80-200.

Singerman, D., Amar, P. (2009) Cairo Cosmopolitan: Politics, Culture, and Urban Space in the New Globalized Middle East, Cairo: The American University in Cairo Press.

Southworth, M. (1989) Theory and Practice of Contemporary Urban Design: A Review of Urban Design Plans in the United States. Liverpool: Liverpool University Press.

Van der Werf, J., Zweerink, K. and van Teeffel, J. (2016) The City at Eye Level - Second and extended version. Delft: Eburon.

Woolley, H. (2003) Urban Open Spaces. New York: Taylor \& Francis.

66 | The Journal of Public Space, 6(I), 202I | ISSN 2206-9658

City Space Architecture / UN-Habitat 